\title{
5. METHODS
}

In 2001, the NSW Department of Health, in conjunction with the 17 area health services and the NSW Commission for Children and Young People, conducted a survey of the health of children in NSW, using computer-assisted telephone interviewing (CATI). The main aim of the New South Wales Child Health Survey 2001 was to provide useful statewide and area health service (AHS) data on the health and wellbeing of children aged $0-12$ resident in NSW, for the purpose of monitoring child health and wellbeing, and for informing health policy and planning. The development of the survey and the methods used are described in detail in an accompanying report. ${ }^{1}$

\section{Survey instrument}

The survey instrument was developed by the Child Health Survey Technical Expert Group (CHSTEG), in consultation with area health services, relevant branches of the NSW Department of Health, and the NSW Health Survey Program Steering Committee (HSPSC). The CHSTEG was established in 1999, as an expert group on the technical aspects of measuring and reporting on child health and wellbeing. The CHSTEG consisted of community paediatricians, public health professionals, child and family health nurses, child health policy analysts, child mental health professionals, health promotion professionals, epidemiologists, and representatives of the NSW Department of Community Services and the Association for Welfare of Child Health (see Acknowledgements). The draft survey instrument was refined, following field-testing and piloting.

The final survey instrument included questions on:

- the social determinants of health, including family functioning, social support, and social capital; childhood activities and childcare, preschool, or school attendance;

- health behaviours, including smoking in pregnancy, smoking in the home, parental smoking messages, infant sleeping position, maternal folate, breastfeeding, nutrition, food security and hunger, sun protection, water safety, and physical activity and inactivity;
- health status, including asthma, oral health, disability, the Child Health Questionnaire (physical-emotionalbehavioural health and impact of family), ${ }^{1}$ emotional and behavioural problems, feeding and behavioural problems in infants, and physical health of toddlers;

- health services, including health services used, immunisation, visits to general practitioners, personal health records, child and family health and parental support services, and home visiting.

The survey instrument was translated into Arabic, Chinese, and Vietnamese, because of the higher proportion of Arabic, Chinese, and Vietnamese women aged 19-54 years, whose English language proficiency was categorised in the $1996 \mathrm{ABS}$ Census as poor or not able to speak English, The survey questionnaire is included as an appendix to this report.

\section{Survey sample}

The target population for the New South Wales Child Health Survey 2001 was NSW residents aged 0-12 years living in households with private telephones. The target sample comprised 500 children aged 0-12 years in each of the 17 area health services (total sample of 8500).

The sampling frame was developed as follows. Records from the Australia on Disk electronic White Pages were geo-coded using MapInfo mapping software., ${ }^{3,4}$ The geocoded telephone numbers were assigned to statistical local areas and area health services. The proportion of numbers for each telephone prefix by area health service was calculated. All prefixes were expanded with suffixes ranging from 0000 to 9999 . The resulting list was then matched back to the electronic White Pages. All numbers that matched numbers in the electronic White Pages were flagged and the number was assigned to the relevant geocoded area health service. Unlisted numbers were assigned to the area health service containing the greatest proportion of numbers with that prefix. Numbers were then filtered to eliminate contiguous unused blocks of greater than 10 numbers. The remaining numbers were then matched to the electronic Yellow Pages to eliminate business numbers. Finally, numbers were randomly sorted.

\section{TABLE 1}

\section{OUTCOMES OF TELEPHONE NUMBERS}

\begin{tabular}{|lr|}
\hline Outcome & Number \\
\hline No answer (10 call backs) or not connected & 56972 \\
Business telephone number or fax number & 21298 \\
No children aged 0-12 years in household & 42202 \\
Household not in NSW or a holiday house & 159 \\
Selected respondent away for duration of survey & 85 \\
Selected respondent confused or deaf & 87 \\
Selected respondent spoke other language not including those being translated & 463 \\
Refusal to participate & 1770 \\
Complete interview & 9425 \\
Total telephone numbers called & 132461 \\
\hline
\end{tabular}




\section{TABLE 2}

\section{COMPLETED INTERVIEWS AND RESPONSE RATE BY AREA HEALTH SERVICE}

\begin{tabular}{|lcc|}
\hline AHS & $\begin{array}{c}\text { Completed } \\
\text { interviews }\end{array}$ & $\begin{array}{c}\text { Response } \\
\text { Rate (per cent) }\end{array}$ \\
\hline Central Coast & 667 & 85.2 \\
Central Sydney & 521 & 80.5 \\
Far West & 622 & 86.1 \\
Greater Murray & 662 & 89.2 \\
Hunter & 508 & 85.8 \\
Illawarra & 509 & 84.0 \\
Macquarie & 514 & 88.5 \\
Mid North Coast & 516 & 87.0 \\
Mid Western & 513 & 86.4 \\
New England & 514 & 88.8 \\
Northern Rivers & 515 & 85.0 \\
Northern Sydney & 525 & 80.9 \\
South Eastern Sydney & 511 & 79.2 \\
Southern & 652 & 88.1 \\
South Western Sydney & 546 & 83.0 \\
Wentworth & 514 & 81.8 \\
Western Sydney & 616 & 83.8 \\
Total & 9425 & 84.2 \\
\hline Response rate $=$ completed interviews / completed \\
interviews + household refusals
\end{tabular}

\section{TABLE 3}

\section{COMPLETED INTERVIEWS BY LANGUAGE}

\begin{tabular}{|lcc|}
\hline Language of interview & Respondents & Per cent \\
\hline English & 9323 & 98.9 \\
Arabic & 27 & 0.3 \\
Chinese & 53 & 0.6 \\
Vietnamese & 22 & 0.2 \\
Total & 9425 & 100.0 \\
\hline
\end{tabular}

When households were contacted, one child aged 0-12 years was selected, using random numbers generated by the CATI system.

\section{Interviews}

Interviews were carried out between March and September 2001. Selected households that were in the electronic White Pages (giving an address for the number) were sent a letter describing the aims and methods of the survey approximately one week before initial telephone contact. A 1800 freecall contact number was provided.

Interviews were carried out by trained interviewers at the NSW Department of Health CATI facility. Up to seven calls were made to make initial contact with a household, and up to 10 calls were made in order to contact the selected respondent. The survey respondent was a parent or main carer of the selected child. Respondents were selected by requesting to speak to 'the person who knows the most about [the child's name's] health'.

\section{Call outcomes and response rates}

During the survey, a total of 132461 telephone numbers were called. The outcome for each of these telephone numbers is shown in Table 1. Only 11830 (8.9\%) of the numbers called yielded an eligible household. The majority of numbers called belonged to households that reported having no children aged $0-12$ years and households where the phone was not answered with 10 call-backs or disconnected. The overall response rate was $84.1 \%$ (completed interviews divided by completed interviews and refusals). The total sample was 9425 children.

Response rates varied by area health service (Table 2) from 79.2 per cent in South Eastern Sydney to 89.2 per cent in Greater Murray. Most respondents (98.9 per cent) were interviewed in English (Table 3). The remaining interviews were conducted in Arabic, Chinese, or Vietnamese. Most survey respondents ( 84.3 per cent) were mothers, followed by fathers (13.9 per cent) (Table 4$)$.

\section{Data analysis}

For analysis, the survey sample was weighted to adjust for differences in the probabilities of selection among subjects, according to the number of eligible children in the household, and the number of residential telephone connections for the household. Post-stratification weights were used to reduce the effect on survey estimates of differing rates of non-response among males and females and children of different ages. These weights used oneyear age groups and Australian Bureau of Statistics mid-year population estimates adjusted to exclude children resident in institutions.

Call and interview data were manipulated and analysed using SAS version 8.02. The SURVEYMEANS procedure was used to calculate standard errors that took into account the stratified sample design. This procedure uses the Taylor expansion method to estimate sampling errors of estimators based on the stratified random sample. ${ }^{5}$

\section{TABLE 4}

\section{COMPLETED INTERVIEWS BY PROXY RESPONDENT}

\begin{tabular}{|lrc|}
\hline Relationship to child & Number & Per cent \\
\hline Mother & 7909 & 84.3 \\
Father & 1321 & 13.9 \\
Stepmother & 22 & 0.2 \\
Stepfather & 17 & 0.2 \\
Grandmother & 80 & 0.7 \\
Grandfather & 9 & 0.1 \\
Legal guardian-Foster parent & 42 & 0.4 \\
Other & 25 & 0.2 \\
Total & 9425 & 100.0 \\
\hline
\end{tabular}




\section{TABLE 5}

SURVEY SAMPLE SIZE AND NSW POPULATION BY AGE GROUP AND SEX

\begin{tabular}{|c|c|c|c|c|c|c|}
\hline \multirow[t]{2}{*}{ Age group (years) } & \multicolumn{3}{|c|}{ Survey sample (unweighted) } & \multicolumn{3}{|c|}{ NSW Population, June 2000} \\
\hline & Males $n(\%)$ & Females $n(\%)$ & Persons $n(\%)$ & Males $N(\%)$ & Females $N(\%)$ & Persons $N(\%)$ \\
\hline $0-4$ & $1814(19.2)$ & $1724(18.3)$ & $3538(37.5)$ & $220936(19.3)$ & $210256(18.4)$ & $431192(37.8)$ \\
\hline $5-7$ & $976(10.4)$ & $1024(10.9)$ & $2000(21.2)$ & $136390(11.9)$ & $129881(11.4)$ & 266271 (23.3) \\
\hline $8-12$ & $1968(20.9)$ & $1919(20.4)$ & 3887 (41.2) & $227968(20.0)$ & $216525(19.0)$ & 444493 (38.9) \\
\hline Total & $4758(50.5)$ & 4667 (49.5) & $9425(100)$ & 585294 (51.3) & $556662(48.7)$ & $1141956(100)$ \\
\hline
\end{tabular}

Source: NSW Child Health Survey 2001 and ABS Estimated Resident Population 2000, excluding people resident in institutions (HOIST)

\section{TABLE 6}

\section{SOCIOECONOMIC DISTRIBUTION OF SURVEY SAMPLE (WEIGHTED) USING THE SEIFA INDEX OF DISADVANTAGE}

\begin{tabular}{|c|c|c|c|c|}
\hline SEIFA & Per cent Population & $\begin{array}{l}\text { Per cent Sample } \\
\text { (weighted) }\end{array}$ & $\begin{array}{l}\text { Lower limit } 95 \% \\
\text { confidence interval } \\
\text { for sample }\end{array}$ & $\begin{array}{c}\text { Upper limit } 95 \% \\
\text { confidence interval } \\
\text { for sample }\end{array}$ \\
\hline Least disadvantaged 1 st quintile & 19.7 & 18.1 & 17.1 & 19.1 \\
\hline 2nd quintile & 19.9 & 24.0 & 22.8 & 25.2 \\
\hline 3rd quintile & 20.4 & 18.8 & 17.8 & 19.8 \\
\hline 4th quintile & 20.1 & 18.3 & 17.4 & 19.3 \\
\hline Most disadvantaged 5th quintile & 19.9 & 20.7 & 19.7 & 21.7 \\
\hline
\end{tabular}

\section{Survival analysis}

The LIFETEST procedure in SAS version 8.02 was used to perform survival analysis on breastfeeding data. ${ }^{5}$ Survival analysis models data that specifies a time between an initial event and a terminating event. The length of time babies received any breastfeeding and full breastfeeding were modelled. The initial event was the commencement of breastfeeding.

The time babies were 'fully breastfed' was determined from the date breastfeeding started (initial event) to the introduction of either solids or a milk substitute, or the date of survey (terminating event). For 'any breastfeeding', the terminating event was the cessation of breastfeeding or the date of survey.

The survival analysis calculated non-parametric estimates of the survival distribution function using the Kaplan-Meier method. The procedure calculated proportions at time intervals, allowing for the weighting of the dataset.

\section{Representativeness of the sample}

Female children were slightly over-represented in the survey sample, comprising 49.5 per cent of the unweighted sample, compared with 48.7 per cent of the population. Conversely, males were under-represented, making up 50.5 per cent of the unweighted sample, compared with 51.3 per cent of the population. Among both sexes, children aged 5-7 years were under-represented in the sample, while children aged 8-12 years were over-represented. After weighting, the age and sex distribution of the survey sample reflected that of the population. Indigenous children comprised 3.8 per cent of the weighted survey sample, similar to their representation in the population ( 3.7 per cent). Children born in Australia were slightly over-represented in the weighted survey sample (96.3 per cent compared with 93.8 per cent in the population).

Compared with the 1996 ABS Census, using the SEIFA index of relative socioeconomic disadvantage, ${ }^{6}$ the survey sample had a slight under-representation of the first (least disadvantaged), third, and fourth quintiles. This coincided with slight over-representation of the second (least disadvantaged) quintile (Table 6).

\section{References}

1. Landgraf JM, Abetz L, Ware JE. The Child Health Questionnaire (CHQ) User's Manual. First Edition. Boston, Mass: The Health Institute, New England Medical Centre, 1996.

2. Quaine J, Eyeson-Annan M, Baker D, O'Sullivan B, Williamson $\mathrm{M}$ and Jorm L. Report on the development of the NSW Child Health Survey 2002. Sydney: Centre for Epidemiology and Research, NSW Department of Health, 2002 (unpublished).

3. Australia on Disk [software]. Sydney: Australia on Disk, November 2000.

4. MapInfo [software]. Troy, NY: MapInfo Corporation, 1997.

5. SAS Institute. The SAS system for Windows version 8.02. Cary NC: SAS Institute Inc., 2001.

6. Australian Bureau of Statistics. Information Paper: 1996 Census-Socioeconomic indices for areas. Canberra: ABS, 1998. ABS Catalogue no. 29120, 1998. 
MAP OF NSW AREA HEALTH SERVICES

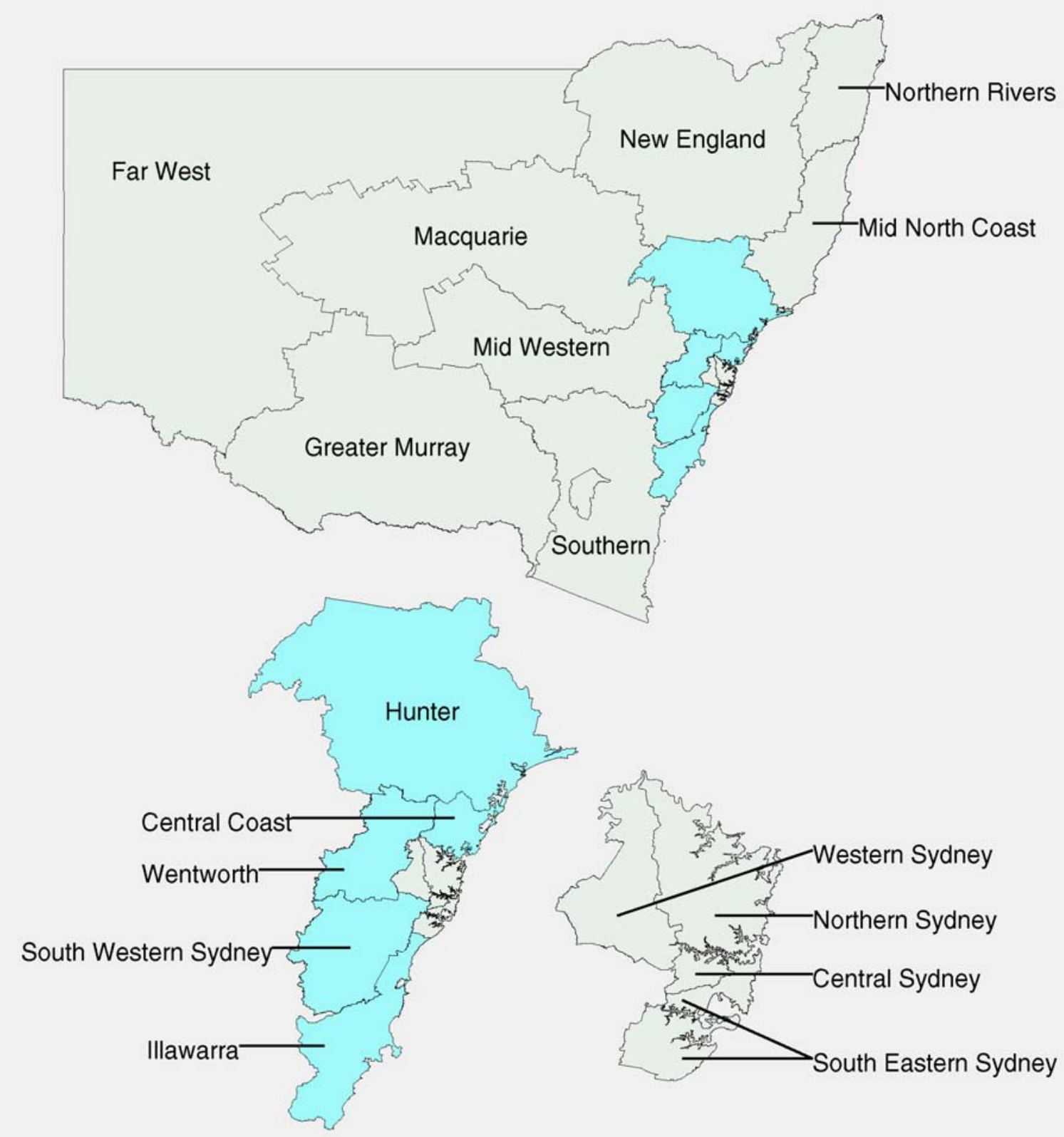

